\title{
Teor de óleo e produtividade da mamoneira de acordo com a adubação nitrogenada e irrigação com água salina
}

\author{
Reginaldo Gomes Nobre(1), Geovani Soares de Lima(1), Hans Raj Gheyi(2), Everaldo Paulo de Medeiros ${ }^{(3)}$, \\ Lauriane Almeida dos Anjos Soares ${ }^{(1)}$ e Allan Nunes Alves ${ }^{(4)}$
}

\begin{abstract}
(1)Universidade Federal de Campina Grande (UFCG), Centro de Ciências e Tecnologia Agroalimentar, Bairro Jardim Rogério, Rua Newton Seixas, oㅜ 333, CEP 58840-000 Pombal, PB. E-mail: rgomesnobre@yahoo.com.br, geovanisoareslima@gmail.com, laurispo@hotmail.com (2)Universidade Federal do Recôncavo da Bahia, Caixa Postal 10078, CEP 44380-000 Cruz das Almas, BA. E-mail: hans@pq.cnpq.br (3)Embrapa Algodão, Laboratório Avançado de Tecnologia Química, Caixa Postal 174, CEP 58428-095 Campina Grande, PB. E-mail: everaldo@cnpa.embrapa.br (4)UFCG, Unidade Acadêmica de Engenharia Agrícola, CEP 58109-970 Campina Grande, PB. E-mail: alan_nunes@yahoo.com.br
\end{abstract}

Resumo - O objetivo deste trabalho foi avaliar o teor de óleo e a produção de sementes da mamoneira 'BRS Energia', submetida a doses de adubação nitrogenada e irrigação com água com diferentes índices de salinidade. $\mathrm{O}$ experimento foi realizado em lisímetros, em condições de campo, em delineamento de blocos ao acaso, com três repetições. Os tratamentos consistiram dos índices salinos da água de 0,4 (controle), 1,4, 2,4, 3,4 e 4,4 $\mathrm{dS} \mathrm{m}^{-1}$, associados a 50,75, 100, 125 e 150\% das doses de $\mathrm{N}$ recomendadas para ensaio. A interação entre salinidade da água de irrigação e doses de $\mathrm{N}$ não foi significativa para nenhuma variável estudada. A salinidade da água até $1,4 \mathrm{dS} \mathrm{m}^{-1}$ propiciou teor de óleo das sementes de $47 \%$. Doses de $\mathrm{N}$ acima de $64 \%$ da recomendada promoveram teor de óleo inferior a $48 \%$. A maior produção de matéria seca da parte aérea foi obtida com $150 \%$ da dose de $\mathrm{N}$ recomendada. $\mathrm{O}$ incremento salino a partir de $0,4 \mathrm{dS} \mathrm{m}^{-1}$ aumenta o tempo para emissão do racemo primário e reduz os valores dos componentes de produção, dos quais a massa de matéria seca da parte aérea e o número de frutos são os mais afetados. Condutividade elétrica da água de até $1,9 \mathrm{dS} \mathrm{m}^{-1}$ e doses de $\mathrm{N}$ a partir de $134 \%$ da recomendada propiciam maior número de racemos.

Termos para indexação: Ricinus communis, componentes de produção, estresse salino.

\section{Oil content and yield of castor bean as affected by nitrogen fertilization and saline water irrigation}

\begin{abstract}
The objective of this work was to evaluate the oil content and seed yield of castor bean 'BRS Energia' subjected to doses of $\mathrm{N}$ fertilization and irrigation water with different levels of salinity. The experiment was carried out in lysimeters, under field conditions, using a randomized complete block design, with three replicates. Treatments consisted of the irrigation-water salinity levels of 0.4 (control), 1.4, 2.4, 3.4 and $4.4 \mathrm{dS} \mathrm{m}^{-1}$, associated to $50,75,100,125$ and $150 \%$ of the recommended $\mathrm{N}$ dose for trials. There was no significant interaction between irrigation water salinity and nitrogen levels for any of the studied variables. Water salinity of up to $1.4 \mathrm{dS} \mathrm{m}^{-1}$ provided $47 \%$ of oil content in seeds. Nitrogen doses $64 \%$ above recommended promoted less than $48 \%$ of oil content. The highest shoot dry weight was obtained with $150 \%$ of the recommended $\mathrm{N}$ dose. Increasing water salinity from $0.4 \mathrm{dS} \mathrm{m}^{-1}$ increases the interval for emission of the primary raceme and reduces the yield components, of which shoot dry weight and number of fruits are the most affected. Electrical conductivity of irrigation water up to $1.9 \mathrm{dS} \mathrm{m}^{-1}$ and $\mathrm{N}$ levels up to $134 \%$ of the recommended dose provide a greater number of racemes.
\end{abstract}

Index terms: Ricinus communis, yield components, saline stress.

\section{Introdução}

A mamoneira (Ricinus communis L.) tem se destacado como alternativa para produção de biocombustíveis e de produtos importantes para diversos segmentos industriais (Rodrigues et al., 2009).

A mamoneira apresenta ampla distribuição geográfica e ocorre de forma frequente nas diversas regiões do Brasil, por suas características xerófilas e heliófilas, além de boa adaptação a distintas condições de solo e manejo (Cavalcanti et al., 2005). É uma oleaginosa passiva de exploração no Semiárido brasileiro, o que dá a possibilidade de ocupação e renda para agricultores familiares da região.

A procura por fontes hídricas tem aumentado e, conforme Medeiros et al. (2003), é notória a escassez

Pesq. agropec. bras., Brasília, v.47, n.7, p.991-999, jul. 2012 
mundial de água em termos quantitativos e qualitativos, principalmente nas regiões áridas e semiáridas, onde se constata a presença de sais nestes recursos. A salinização da água restringe seu uso para o consumo humano e animal, e para a irrigação. $\mathrm{O}$ rápido aumento no uso doméstico, industrial e agrícola de água fresca tem agravado a escassez desse recurso, em todo o mundo. Dessa forma, o aproveitamento na irrigação de fontes de água com qualidade inferior, como as salinas, vem sendo considerado como alternativa importante na utilização dos recursos naturais escassos. Embora as águas salinas sejam consideradas inadequadas para a irrigação, há amplas evidências da viabilidade de seu uso, desde que se adotem técnicas de manejo adequadas e culturas tolerantes à salinidade (Rhoades et al., 2000).

Altas concentrações de sais, além de reduzir o potencial osmótico do solo, podem provocar efeitos tóxicos nas plantas e causar distúrbios funcionais bem como dano ao metabolismo (Silva et al., 2003). A redução no potencial hídrico dos tecidos, causada pelo excesso de sais, provoca restrição no crescimento, pois as taxas de elongação e de divisão celular dependem diretamente da extensibilidade da parede celular. Portanto, o ajustamento osmótico é essencial para o crescimento dos vegetais em meio salino (Ashraf \& Harris, 2004).

O uso do óleo de mamona como matéria-prima para produção de biocombustível demandará a busca por melhores tecnologias de cultivo - irrigação, adubação, entre outras -, de modo a possibilitar a plena utilização de seu potencial (Marinho et al., 2010). O N é um macronutriente comumente associado a aumentos na produtividade e rentabilidade das culturas (Miller \& Cramer, 2005; Chaves et al., 2011). De acordo com Flores et al. (2002), a alta dependência das culturas em $\mathrm{N}$ decorre de suas funções no metabolismo das plantas, em que participa como constituinte da molécula de clorofila, ácidos nucleicos, aminoácidos e proteínas.

O objetivo deste trabalho foi avaliar o teor de óleo e a produção de sementes de mamoneira irrigada com água com diferentes índices de salinidade e sob distintas doses de nitrogênio.

\section{Material e Métodos}

A pesquisa foi realizada em lisímetros, em condições de campo, entre outubro de 2010 e fevereiro de 2011, em área experimental do Centro de Ciências e Tecnologia Agroalimentar, da Universidade Federal de Campina Grande (CCTA/UFCG), Pombal, PB (6º $48^{\prime} 16^{\prime \prime} \mathrm{S}$, $37^{\circ} 49^{\prime} 15^{\prime \prime} \mathrm{W}$, à altitude média de $144 \mathrm{~m}$ ).

$\mathrm{O}$ experimento foi realizado em delineamento experimental de blocos ao acaso, em arranjo fatorial $5 \times 5$, com três repetições, no total de setenta e cinco unidades experimentais. Os tratamentos consistiram da combinação de cinco níveis de condutividade elétrica da água de irrigação $(\mathrm{CEa})-\mathrm{S}_{1}, 0,4$ controle; $\mathrm{S}_{2}, 1,4 ; \mathrm{S}_{3}, 2,4 ; \mathrm{S}_{4}, 3,4 ;$ e $\mathrm{S}_{5}, 4,4 \mathrm{dS} \mathrm{m}^{-1}-\mathrm{e}$ cinco doses de adubação nitrogenada $-\mathrm{N}_{1}, 50 ; \mathrm{N}_{2}, 75 ; \mathrm{N}_{3}, 100$; $\mathrm{N}_{4}, 125$; e $\mathrm{N}_{5}, 150 \%$ da adubação nitrogenada indicada (100 mg kg-1) para ensaios em vaso (Novais et al., 1991). Um terço da adubação com $\mathrm{N}$ foi aplicado em fundação, e os $2 / 3$ restantes foram parcelados em cinco vezes, aplicados a intervalos de 11 dias a partir dos 24 dias após a semeadura (DAS). As fontes utilizadas foram ureia e fosfato monoamônio.

Os diferentes níveis de salinidade da água foram obtidos pela adição de cloreto de sódio $(\mathrm{NaCl})$ à água proveniente do sistema de abastecimento local, cuja quantidade (Q) foi determinada pela equação $\mathrm{Q}\left(\mathrm{mg} \mathrm{L}^{-1}\right)=\mathrm{CEa} \times 640$, conforme Rhoades et al. (2000), em que CEa $\left(\mathrm{dS} \mathrm{m}^{-1}\right)$ representa o valor desejado da condutividade elétrica da água. A água escolhida como

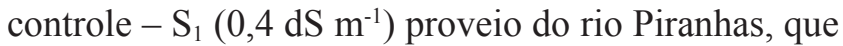
abastece cidades do Cariri paraibano e fornece água para irrigação de cultivos diversos.

Utilizou-se a cultivar de mamoneira BRS Energia, com sementes cedidas pela Embrapa Algodão. Silva et al. (2009) relatam que esta cultivar é adaptada às condições de solo e clima da Região Nordeste, possui porte baixo (média de $106 \mathrm{~cm}$ ), frutos semi-indeiscentes, produtividade média de $1.940 \mathrm{~kg} \mathrm{ha}^{-1}$ por ano e ciclo de 110 dias.

Utilizaram-se recipientes de plástico de $100 \mathrm{~L}$ de capacidade, preenchidos com $2 \mathrm{~kg}$ de brita (n⿳⺈ 0 ) que cobria a base do vaso, seguida de $107,8 \mathrm{~kg}$ de solo (Neossolo Regolítico eutrófico tipo areia franca), não salino e não sódico, coletado à profundidade de $0-30 \mathrm{~cm}$ do solo e proveniente do Município de Pombal, PB. As análises físicas e químicas do solo (Tabela 1) foram realizadas no Laboratório de Solos e Nutrição de Plantas (LSNP) da UFCG, conforme metodologia descrita por Claessen (1997). Cada recipiente possuía dois furos na base, para permitir a drenagem e, abaixo dos mesmos furos, um microtubo de $12 \mathrm{~mm}$ de diâmetro conectava 
a base a duas garrafas de plástico de $2 \mathrm{~L}$, para coleta do volume drenado e estimativa do consumo de água pela cultura.

A adubação de fundação foi realizada com $162,5 \mathrm{~g}$ de superfosfato simples, $12 \mathrm{~g}$ de sulfato de potássio $\left(\mathrm{K}_{2} \mathrm{SO}_{4}\right)$ e $2,2 \mathrm{~kg}$ (equivalentes a $2 \%$ ) de húmus de minhoca $\left(6,3 \mathrm{~g}\right.$ de $\mathrm{N} \mathrm{kg}^{-1}, 1,28 \mathrm{~g} \mathrm{~kg}^{-1}$ de $\mathrm{P}$ e $0,53 \mathrm{~g} \mathrm{~kg}^{-1} \mathrm{de} \mathrm{K}$ ) por vaso, para melhorar as propriedades físicas, químicas e biológicas do solo, de forma a aumentar a capacidade de retenção e infiltração da água. Após o acondicionamento do material do solo nos recipientes, aplicou-se, conforme tratamento, o volume de água necessário para atingir a capacidade de campo.

A semeadura foi realizada em 28 de outubro de 2010, com dez sementes por recipiente, de forma equidistante, a dois $\mathrm{cm}$ de profundidade. A emergência das plântulas iniciou-se aos seis DAS e continuou até o décimo terceiro dia, e o primeiro desbaste realizou-se aos 14 DAS, tendo-se deixado em cada parcela as quatro plântulas que apresentavam maior vigor. Aos 21, 35 e 46 DAS realizaram-se novos desbastes, tendo-se eliminado uma planta por recipiente.

A partir do início da emissão das flores, realizaram-se duas adubações foliares (29 e 37 DAS), com o fertilizante Albatroz $\left(\mathrm{N}, 10 \% ; \mathrm{P}_{2} \mathrm{O}_{5}, 52 \% ; \mathrm{K}_{2} \mathrm{O}, 10 \%\right.$; Ca, $0,1 \%$; Zn, $0,02 \%$; B, 0,02\%, Fe, 0, $15 \%$; Mn, 0,1\%; $\mathrm{Cu}, 0,02 \%$; e Mo, 0,005\%), à proporção de $1 \mathrm{~g} \mathrm{~L}^{-1}$, tendo-se aplicado $5 \mathrm{~L}$ em todas as plantas, com um pulverizador costal.

As irrigações foram realizadas diariamente às $17 \mathrm{~h}$, de acordo com a necessidade hídrica das plantas, e a lâmina aplicada foi determinada pelo balanço hídrico - volume aplicado menos o drenado -, acrescido de fração de lixiviação média de $10 \%$.

Os tratos culturais consistiram da eliminação manual de plantas daninhas, escarificação superficial do solo antes de cada irrigação, e tutoramento das plantas após atingirem o estádio de floração. Para o manejo preventivo de pragas, foram realizadas duas pulverizações ao longo da condução do experimento, com Abamectina.

Para determinação do efeito dos tratamentos sobre as variáveis de produção, foram analisados: o número de dias para emissão do racemo primário (NDRP); o comprimento do racemo primário $(\mathrm{CR})$; o número de racemos por planta (NRP); o número de frutos totais por planta (NFruT); a massa de 100 sementes do racemo primário (MCSrp) e do secundário (MCSrs); o teor de óleo no racemo primário (TOrp) e no secundário (TOrs); e a massa de matéria seca da parte aérea (FSPA).

O NDRP foi estimado por meio do acompanhamento diário do surgimento da inflorescência. O CR foi mensurado aos 88 DAS, conforme a distância entre a inserção dos frutos na base e o ápice do racemo, e o NRP foi determinado aos 120 DAS. A colheita dos racemos foi realizada manualmente, quando $90 \%$ dos frutos atingiram a maturação fisiológica, tendo sido completada a secagem por exposição ao sol por três dias. Após a secagem, determinou-se o número de frutos colhidos e, a partir do somatório de todos os frutos produzidos durante o ciclo da cultura (120 dias), mensurou-se o NFruT. Após a secagem, os frutos eram debulhados manualmente e, em seguida, mensuravamse a MCSrp e a MCSrs.

O teor de óleo nas sementes foi determinado no Laboratório Multidisciplinar da Embrapa Algodão, em Campina Grande, PB, após a secagem e beneficiamento, com umidade corrigida para $10 \%$, de forma não destrutiva e com uso de um espectrômetro de ressonância magnética nuclear (RMN) $\mathrm{H}^{1}$ Oxford MQA 7005 (American Oil Chemists' Society, 2000). Aos 120 DAS, as plantas foram cortadas rente ao solo, e as folhas e os caules foram colocados em sacos de papel, devidamente identificados, e postos em estufa de circulação forçada de ar a $65^{\circ} \mathrm{C}$ por 72 horas, até atingir massa constante; em seguida, determinou-se a FSPA.

Os dados obtidos foram analisados mediante análise de variância pelo teste $\mathrm{F}$ e, nos casos de significância,

Tabela 1. Características físicas e químicas do Neossolo utilizado no experimento.

\begin{tabular}{|c|c|c|c|c|c|c|c|c|c|c|}
\hline $\begin{array}{l}\text { Densidade } \\
\left(\mathrm{kg} \mathrm{dm}^{-3}\right)\end{array}$ & $\begin{array}{c}\text { Porosidade total } \\
\qquad(\%)\end{array}$ & Areia & $\begin{array}{l}\text { Silte } \\
-\left(\mathrm{g} \mathrm{kg}^{-1}\right.\end{array}$ & Argila & $\mathrm{Ca}^{+2}$ & $\begin{array}{l}\mathrm{Mg}^{+2} \\
-(\mathrm{cm}\end{array}$ & $\mathrm{Na}^{(1)}$ & $\mathrm{K}^{+}$ & $\mathrm{pH}$ & $\begin{array}{c}\mathrm{CE}_{\mathrm{as}} \\
\left(\mathrm{dS} \mathrm{m}^{-1}\right)\end{array}$ \\
\hline 1,31 & 48,22 & 830 & 71 & 99 & 7,50 & 5,15 & 0,29 & 0,29 & 7,33 & 0,53 \\
\hline
\end{tabular}

${ }^{(1)} \mathrm{Ca}^{2+} \mathrm{e} \mathrm{Mg}^{2+}$ extraídos com $\mathrm{KCl} 1 \mathrm{~mol} \mathrm{~L}^{-1} \mathrm{pH} 7,0 ; \mathrm{Na}^{+}$e K extraídos por meio de $\mathrm{NH}_{4} \mathrm{OAc} 1$ mol L-1 $\mathrm{pH} 7,0$. 
realizaram-se as análises de regressão polinomial linear, quadrática e cúbica, pelo programa estatístico Sisvar.

\section{Resultados e Discussão}

Houve efeito significativo da salinidade da água de irrigação sobre todas as variáveis estudadas, e efeito significativo das doses de adubação nitrogenada sobre o NRP, o TOrp, o TOrs e FSPA (Tabela 2). A interação entre a salinidade da água de irrigação e as doses de adubação nitrogenada não teve efeito significativo sobre nenhuma das variáveis estudadas. Santos et al. (2010), em estudo com a mamoneira sob fertilização com distintas doses de cama de galinha, e Severino et al. (2006), que utilizaram doses crescentes de esterco bovino, constataram que os componentes de produção da mamoneira respondem positivamente à adubação. Lima et al. (2011) analisaram os efeitos da irrigação com água de diferentes salinidades e doses de $\mathrm{N}$ no crescimento inicial da mamoneira, e também não encontraram interação entre os fatores.

A condutividade elétrica da água de irrigação afetou significativamente o NDRP (Tabela 2); e o incremento da salinidade da água de irrigação promoveu acréscimo linear nessa variável, de $2,1 \%$, por aumento unitário da CEa, ou seja, retardou em três dias o aparecimento do racemo primário das plantas irrigadas com água a 4,4 dS m${ }^{-1}$, em comparação ao controle (Figura 1). Conforme Rhoades et al. (2000), a redução na absorção de água e nutrientes pela planta, em consequência da diminuição do potencial osmótico do solo, prolonga o ciclo da cultura. Resultados nesse sentido também foram encontrados por Silva et al. (2008) que, ao avaliar o comportamento da mamoneira 'BRS Energia', em casa de vegetação sob distintas CEa $\left(0,7\right.$ a $\left.6,7 \mathrm{dS} \mathrm{m}^{-1}\right)$, verificaram que o número de dias para emissão da primeira inflorescência teve incremento de $7,1 \%$ por aumento unitário da $\mathrm{CEa}$. A diferença entre os resultados entre os estudos pode ser atribuída à diferença da faixa de $\mathrm{CEa}$ estudada ou às condições de execução (campo vs casa de vegetação).

O comprimento do racemo tem implicação direta sobre o número de frutos da mamoneira, e esta variável foi significativamente influenciada pelos níveis da $\mathrm{CEa}$ (Tabela 2). Os dados ajustaram-se ao modelo linear, tendo-se observado decréscimos no CR de 5,8\% por aumento unitário da $\mathrm{CEa}$, ou seja, redução de 23,3\% $(5,6 \mathrm{~cm})$ no $\mathrm{CR}$ das plantas irrigadas com água a 4,4 dS m-1, em comparação ao controle (Figura 1). Tester \& Davenport (2003) afirmam que a redução do potencial osmótico da solução do solo provocada pelo acúmulo de sais dificulta a absorção de água nas células e prejudica o desenvolvimento e a produção das culturas.

Observou-se efeito linear decrescente da CEa sobre o NRP, com decréscimo de $14,2 \%$ por incremento unitário da $\mathrm{CEa}$, ou seja, redução de $56,7 \%$ no número de racemos das plantas irrigadas com CEa de $4,4 \mathrm{dS} \mathrm{m}^{-1}$,

Tabela 2. Significância dos tratamentos sobre as variáveis número de dias para emissão do racemo primário (NDRP), comprimento do racemo primário (CR), número de racemos por planta (NRP), número de frutos totais por planta (NFruT), massa de cem sementes dos racemos primários (MCSrp) e secundários (MCSrs), teor de óleo do racemos primários (TOrp) e secundários (TOrs) e massa de matéria seca da parte aérea (FSPA) da mamoneira, em consequência da aplicação de diferentes níveis de salinidade da água de irrigação e doses de nitrogênio.

\begin{tabular}{|c|c|c|c|c|c|c|c|c|c|}
\hline \multirow[t]{2}{*}{ Fonte de Variação } & \multicolumn{9}{|c|}{ Teste $\mathrm{F}^{(1)}$} \\
\hline & NDRP & CR & NRP & NFruT & MCSrp & MCSrs & TOrp & TOrs & FSPA \\
\hline Salinidade da água (S) & $*$ & $*$ & $* *$ & $* *$ & $* *$ & $* *$ & $* *$ & $* *$ & $* *$ \\
\hline Regressão. linear & $* *$ & $*$ & $* *$ & $* *$ & $* *$ & $* *$ & $* *$ & $* *$ & $* *$ \\
\hline Regressão quadrática & ns & ns & ns & ns & ns & ns & $*$ & ns & ns \\
\hline Regressão cúbica & ns & $\mathrm{ns}$ & ns & ns & $\mathrm{ns}$ & $\mathrm{ns}$ & ns & $\mathrm{ns}$ & $* *$ \\
\hline Doses de nitrogênio (N) & ns & ns & $* *$ & ns & $\mathrm{ns}$ & ns & $* *$ & $* *$ & $* *$ \\
\hline Regressão linear & - & - & $* *$ & - & - & - & $* *$ & $* *$ & $* *$ \\
\hline Regressão quadrática & - & - & ns & - & - & - & ns & ns & ns \\
\hline Regressão cúbica & - & - & ns & - & - & - & ns & $\mathrm{ns}$ & $\mathrm{ns}$ \\
\hline Interação (SxN) & $\mathrm{ns}$ & $\mathrm{ns}$ & ns & $\mathrm{ns}$ & $\mathrm{ns}$ & $\mathrm{ns}$ & ns & ns & $\mathrm{ns}$ \\
\hline Bloco & $*$ & $*$ & ns & $*$ & ns & ns & $*$ & ns & ns \\
\hline CV (\%) & 9,2 & 12,4 & 29,2 & 19,3 & 9,5 & 13,3 & 8,0 & 14,1 & 11,6 \\
\hline
\end{tabular}

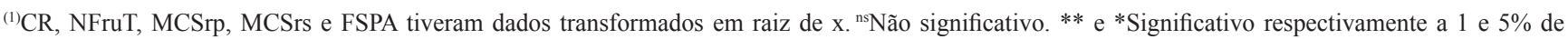
probabilidade, pelo teste F. 
em comparação ao controle (Figura 2). Quanto ao fator dose de N, observou-se resposta linear e crescente, com incremento no NRP de 7,1\%, em razão do aumento de $25 \%$ da dose de $\mathrm{N}$ estudada, tendo-se obtido o maior número de racemos por planta $(7,4)$, com a aplicação de $150 \%$ da dose recomendada de N. Conforme Nóbrega et al. (2001), o número de racemos por planta de mamoneira é considerado baixo quando menor
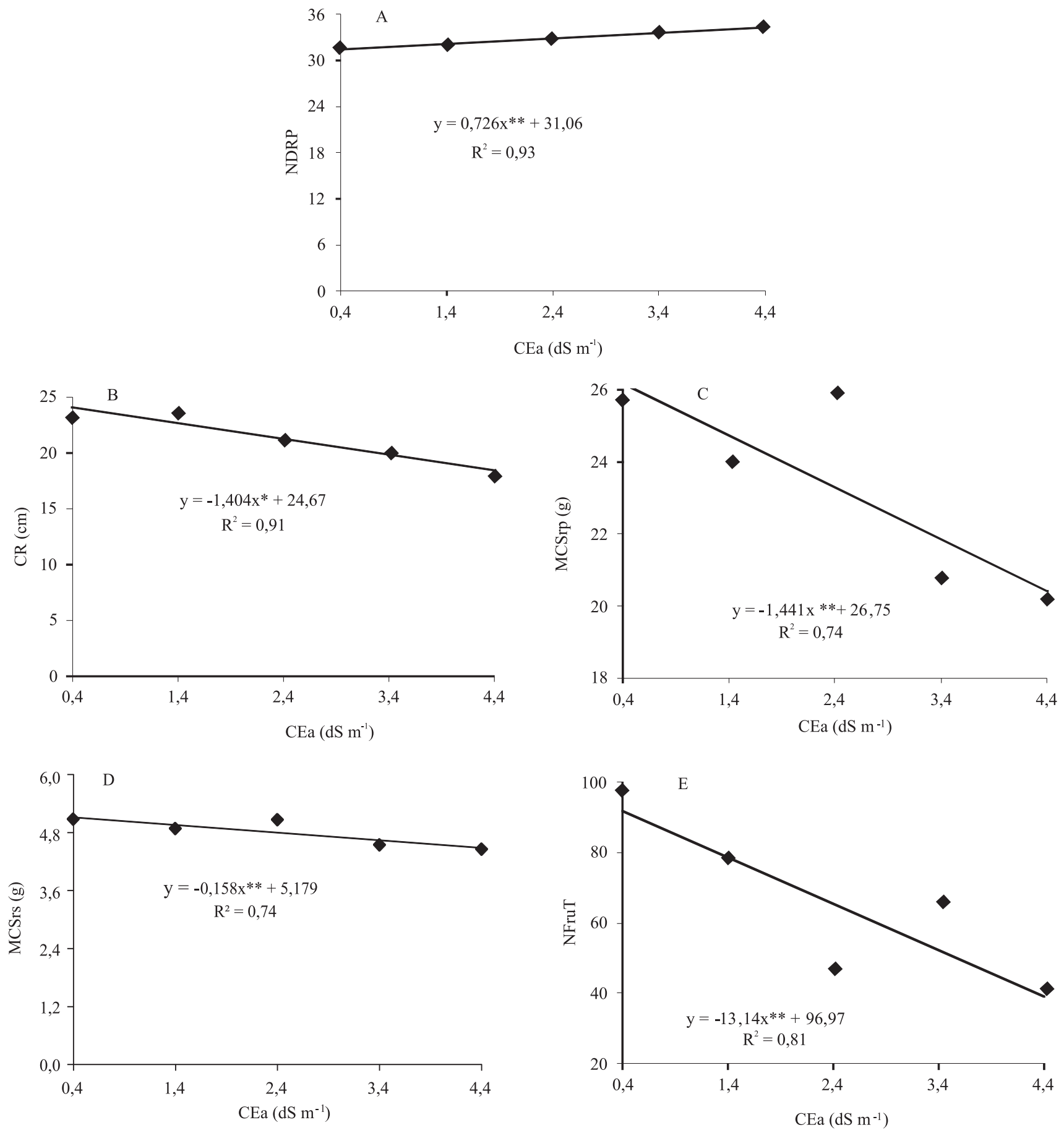

Figura 1. Efeitos da condutividade elétrica da água de irrigação (CEa) sobre: A, número de dias para emissão do racemo primário (NDRP); B, comprimento de racemo primário (CR); C, massa de 100 sementes nos racemos primários (MCSrp); D, massa de 100 sementes nos racemos sucundários (MCSrs); e E, número de frutos totais por planta (NFruT). 
que 3, médio, entre 3 e 7, e alto quando maior que 7 . Assim, verifica-se que as plantas submetidas à CEa de até $1,9 \mathrm{dS} \mathrm{m}^{-1}$ e doses de $\mathrm{N}$ superiores a $134 \%$ tiveram alta produção de racemos, e os demais tratamentos tiveram produção média de racemos. Silva et al. (2007) estudaram a adubação nitrogenada em cobertura, no híbrido Sara de mamoneira, e não constataram efeito
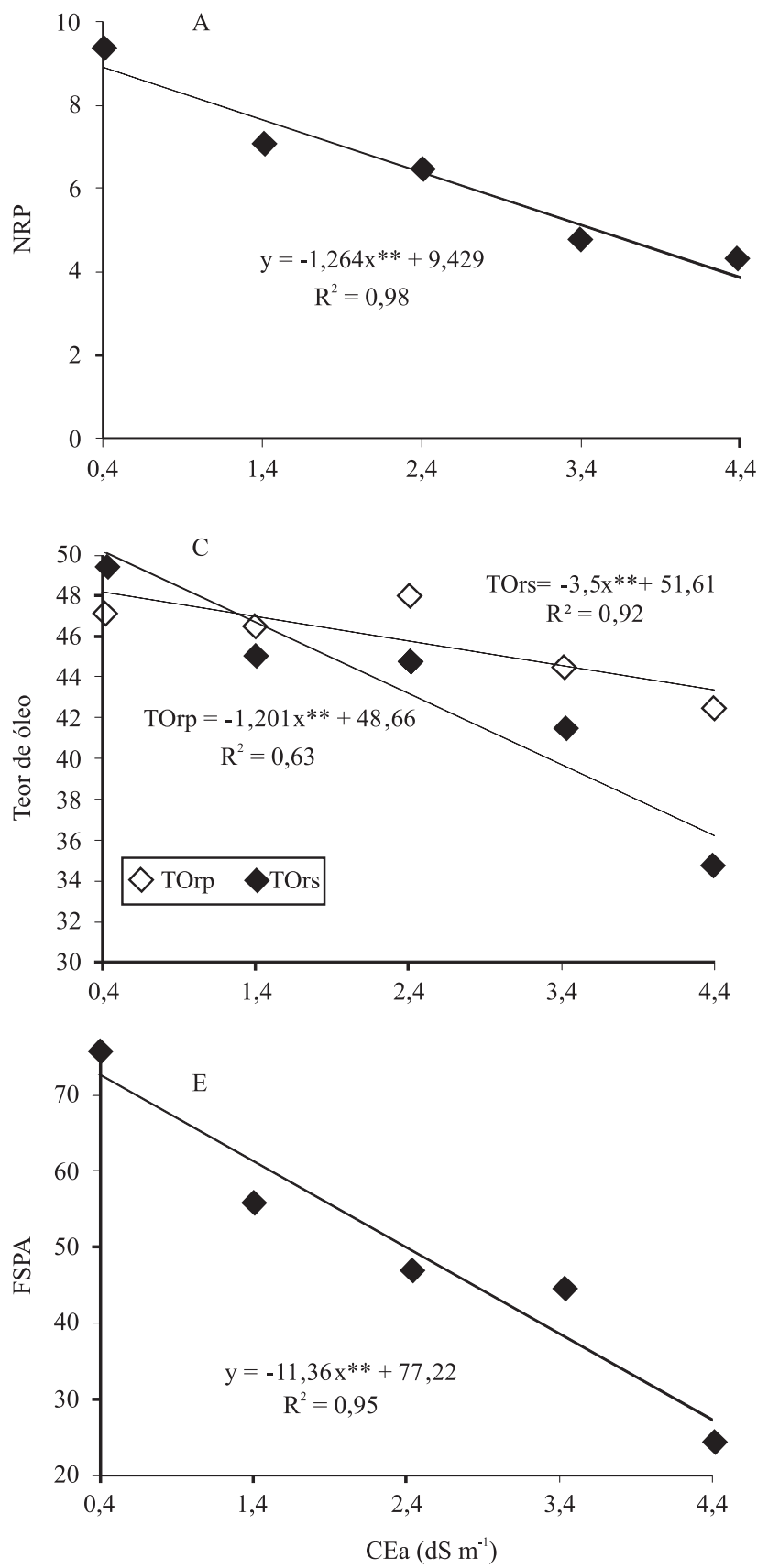

significativo de N sobre o NRP, em estudo conduzido em condição não salina. Assim, pode-se inferir que o efeito benéfico do $\mathrm{N}$ sobre o NRP, em condição de estresse salino, pode superar os efeitos negativos da salinidade.

A salinidade da água influenciou significativamente o NFruT e, conforme o constatado para o CR, o
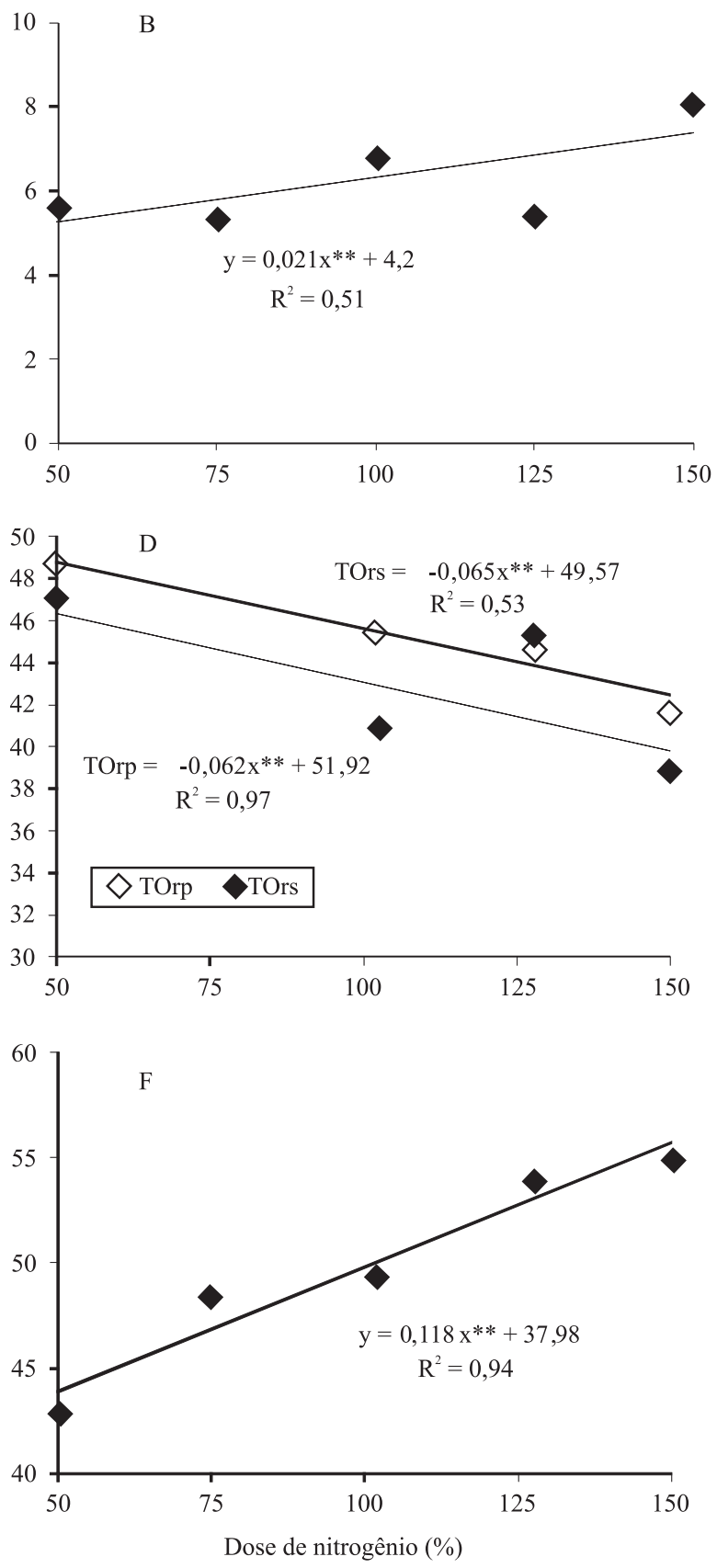

Figura 2. Efeitos da condutividade elétrica da água de irrigação (CEa) e de doses de nitrogênio sobre o número de racemos por planta (NRP), o teor de óleo em racemos primários (TOrp) e secundários (TOrs), e sobre massa de matéria seca da parte aérea (FSPA) de mamoneira. 
aumento da CEa reduziu linearmente essa variável, com decréscimos de $14,3 \%$ por incremento unitário da $\mathrm{CEa}$, ou seja, houve redução de 53 frutos $(57,3 \%)$ por planta submetida à CEa de $4,4 \mathrm{dS} \mathrm{m}^{-1}$, em comparação à testemunha (Figura 1). Segundo Rhoades et al. (2000), a salinidade afeta não apenas o desenvolvimento, mas também a produção das culturas, efeito que se manifesta principalmente na redução da população e do desenvolvimento dos frutos, com sintomas similares ao do estresse hídrico. Silva et al. (2008), em estudo com a mamoneira sob distintas $\mathrm{CEa}$, observaram redução de $86 \%$ no número de frutos por cacho, nas plantas da 'BRS Energia' irrigadas com CEa de 4,7 dS m${ }^{-1}$, em relação àquelas sob $0,7 \mathrm{dS} \mathrm{m}^{-1}$, tendo verificado, ainda, que a cultivar BRS Paraguaçu não frutificou, quando submetida à irrigação com água de $4,7 \mathrm{dS} \mathrm{m}^{-1}$.

A salinidade da água de irrigação promoveu efeitos significativos sobre MCSrp e MCSrs, com decréscimos de 5,5 e 3,1\%, respectivamente, por aumento unitário da CEa, ou seja, redução de 22,0\% (5,76 g) na MCSrp e $12,4 \%(0,64 \mathrm{~g})$ na MCSrs das plantas submetidas à CEa de $4,4 \mathrm{dS} \mathrm{m}^{-1}$, em comparação às irrigadas com $0,4 \mathrm{dS} \mathrm{m}^{-1}$ (Figura 1). Plantas sob estresse salino podem ter acúmulo de sais nas vias transpiratórias, o que provoca danos nos tecidos foliares, leva à inibição mais acentuada da fotossíntese e, por consequência, afeta as variáveis de crescimento e produção (Munns et al., 2006).

Com as mesmas tendências já observadas para NFruT e NRP, a massa das sementes foi também afetada pela salinidade da água de irrigação. Conforme Gulzar et al. (2003), os estresses provocados pelo excesso de íons, em geral, diminuem a assimilação de $\mathrm{CO}_{2}$, condutância estomática, transpiração e fotossíntese das plantas e, consequentemente, acabam por prejudicar a produção e a produtividade das culturas. Redução de produção ocasionada pela salinidade também foi constatada por Correia et al. (2005), que avaliaram a produção do amendoim, em condições de diferentes níveis de salinidade da água de irrigação, e verificaram que o estresse salino promoveu decréscimo linear na massa de frutos e sementes secos.

$\mathrm{O}$ aumento da $\mathrm{CEa}$ proporcionou efeito linear e decrescente sobre TOrp e TOrs (Figura 2), com decréscimos de 2,5 e 7,0\%, respectivamente, por aumento unitário da $\mathrm{CEa}$, ou seja, redução de 10,0\% no TOrp e de $27,9 \%$ no TOrs das plantas irrigadas com água de $4,4 \mathrm{dS} \mathrm{m}^{-1}$ em comparação às irrigadas com
0,4 $\mathrm{dS} \mathrm{m}^{-1}$. Os efeitos antagônicos dos sais dissolvidos nas águas ou nos solos, na maioria das vezes, promovem inibição e desuniformidade do crescimento, declínio na produção e na qualidade dos produtos obtidos das plantas cultivadas (Ayers \& Westcot, 1999).

Constata-se que, à medida em que a massa das 100 sementes aumentou, ocorreu incremento em seu teor de óleo, tanto nas provenientes do racemo primário como do secundário, com correlação positiva $\left(\mathrm{R}^{2}=0,92\right)$ em ambos os casos. Sousa et al. (2011) também verificaram correlação positiva $\left(\mathrm{R}^{2}=0,99\right)$ entre estas variáveis, na cultura do pinhão-manso sob distintas lâminas com água residuária, e encontraram incremento no teor de óleo com o aumento da lâmina de água aplicada. Para Jellum et al. (1973), o teor de óleo é mais dependente do material genético do que do ambiente. Duarte et al. (2005) avaliaram nove cultivares de milho e, diferentemente do presente trabalho, não verificaram correlação entre massa das sementes e teor de óleo.

Severino et al. (2006) citam que a cultivar BRS Energia possui teor de óleo médio de $48 \%$ nas sementes; neste sentido, no presente estudo, verificouse que as plantas irrigadas com CEa de até $0,6 \mathrm{dS} \mathrm{m}^{-1}$ proporcionaram TOrp de 48\% (Figura 2). No entanto, em relação ao TOrs foi menos sensível ao aumento de CEa. Constatou-se, ainda, que mesmo as plantas irrigadas com CEa de $1,4 \mathrm{dS} \mathrm{m}^{-1}$ tiveram produção de óleo nos racemos primários e secundários acima de $47 \%$.

Os teores de óleo do racemo primário e do secundário também foram afetados pelas doses de adubação nitrogenada (Figura 2), com efeito linear, tendo ocorrido redução de 3,6\% no TOrp e de 3,5\% no TOrs das plantas, pelo aumento de $25 \%$ das doses de $\mathrm{N}$, ou seja, decréscimos em TOrp e TOrs de, respectivamente, 14,6 e 14,0\% entre as doses N5 (150\% de N recomendada) e N1 (50\%). Não se tem observado efeitos significativos da adubação nitrogenada no teor de óleo nos grãos (Jellum et al., 1973; Duarte et al., 2005). Silva et al. (2007) estudaram o efeito de doses de $\mathrm{N}$ de 0 a $120 \mathrm{~kg} \mathrm{ha}^{-1}$ sobre o teor de óleo das sementes do híbrido Sara de mamoneira e não verificaram aumento no teor de óleo em consequência da adubação nitrogenada. Melhorança \& Staut (2005) afirmaram que, em cultivares comerciais de mamoneira, o teor médio de óleo é de $48 \%$. Verifica-se, no presente estudo que, em termos de TOrp, as plantas que receberam doses de $\mathrm{N}$ de até $64 \%$ tiveram teor de óleo de $48 \%$; 
em relação ao TOrs, com valores de $\mathrm{N}$ acima de $50 \%$, as plantas produziram teores de óleo inferiores a $48 \%$, e o maior valor (46,3\%) foi obtido com $50 \%$ de $\mathrm{N}$.

$\mathrm{O}$ aumento dos níveis salinos da água de irrigação influenciou significativamente a massa de matéria seca da parte aérea (FSPA) das plantas de mamoneira 'BRS Energia' (Figura 2), e a resposta das plantas foi linear, com decréscimo da FSPA de 15,6\% por aumento unitário da condutividade elétrica da água de irrigação, ou seja, redução de $62,5 \%(45,44 \mathrm{~g})$ na FSPA das plantas sob CEa de $4,4 \mathrm{dS} \mathrm{m}^{-1}$, em comparação à testemunha. Cavalcanti et al. (2004), ao avaliar os efeitos da salinidade da água de irrigação sobre o crescimento inicial da cultura da mamoneira 'BRS 149 Nordestina', em ambiente protegido, constataram que a FSPA decresceu em média $6 \%$ por aumento unitário da CEa.

Em relação ao efeito da adubação nitrogenada sobre a FSPA, observa-se (Figura 2) que os dados se ajustaram ao modelo linear, tendo ocorrido incremento de $5,3 \%$ com o aumento de $25 \%$ da dose de $\mathrm{N}$, o que indica aumento de $21,2 \%(11,8 \mathrm{~g})$ entre a dose de $50 \%$ e a de $150 \%$ de N. Estes resultados concordam com os de Chaves et al. (2011) que, ao analisar o efeito da adubação nitrogenada sobre a produção de matéria seca da mamoneira, constataram aumento desta variável em consequência do incremento da dose de $\mathrm{N}$ aplicada. Silva et al. (2007) não verificaram efeito das doses de $\mathrm{N}$ aplicadas em cobertura, sobre a produção de matéria seca de plantas de mamoneira do híbrido Sara.

\section{Conclusões}

1. Os efeitos da adubação nitrogenada e os da salinidade da água de irrigação sobre o desenvolvimento e produtividade da mamoneira são independentes.

2. Os efeitos salinidade da água de irrigação sobre o teor de óleo dos racemos são de pequena magnitude, até $1,4 \mathrm{dS} \mathrm{m}^{-1}$, e mais pronunciados em racemos primários do que em secundários.

3. A adubação nitrogenada tem efeito linear negativo sobre os teores de óleo de sementes e positivo sobre a produção de matéria seca da parte aérea.

4. O incremento da salinidade da água aumenta o tempo para emissão do racemo primário e reduz os valores dos componentes de produção da mamoneira 'BRS Energia', e a massa de matéria seca da parte aérea e o número de frutos por plantas são as variáveis mais afetadas.

\section{Agradecimentos}

Ao Conselho Nacional de Pesquisa e Desenvolvimento Científico e Tecnológico, pelo financiamento do projeto e concessão de bolsa; à Embrapa Algodão, pelo fornecimento das sementes de mamona.

\section{Referências}

AMERICAN OIL CHEMISTS' SOCIETY. Official methods and recommended practices of the AOCS. $5^{\text {th }}$ ed. Champaign: AOCS, 2000.

ASHRAF, M.; HARRIS, P.J.C. Potential biochemical indicators of salinity tolerance in plants. Plant Science, v.166, p.3-16, 2004.

AYERS, R.S.; WESTCOT, D.W. A qualidade da água na agricultura. 2.ed. Campina Grande: UFPB, 1999. 218p. (Estudos FAO. Irrigação e drenagem, 29).

CAVALCANTI, M.L.F.; BARROS JÚNIOR, G.; CARNEIRO, P.T.; FERNANDES, P.D.; GHEYI, H.R.; CAVALCANTI, R.S. Crescimento inicial da mamoneira submetido à salinidade da água de irrigação. Revista de Biologia e Ciências da Terra, v.4, p.1-8, 2004.

CAVALCANTI, M.L.F.; FERNANDES, P.D.; GHEYI, H.R.; BARROS JÚNIOR, G.; SOARES, F.A.L.; SIQUEIRA, E. da C. Índices ecofisiológicos da mamoneira sob estresse salino. Revista Brasileira de Engenharia Agrícola e Ambiental, v.9, p.66-70, 2005.

CHAVES, L.H.G.; GHEYI, H.R.; RIBEIRO, S. Consumo de água e eficiência do uso para cultivar de mamona Paraguaçu submetida à fertilização nitrogenada. Engenharia Ambiental, v.8, p.126-133, 2011.

CLAESSEN, M.E.C. (Org.). Manual de métodos de análise de solo. 2.ed. rev. atual. Rio de Janeiro: Embrapa-CNPS, 1997. 212p. (Embrapa-CNPS. Documentos, 1).

CORREIA, K.G.; FERNANDES, P.D.; GHEYI, H.R.; GURGEL, M.T.; RODRIGUES, L.N. Crescimento do amendoinzeiro irrigado com águas salinas. Revista Brasileira de Engenharia Agrícola e Ambiental, v.9, p.81-85, 2005. Suplemento.

DUARTE, A.P.; MASON, S.C.; JACKSON, D.S.; KIEHL, J.C. Grain quality of Brazilian maize genotype as influenced by nitrogen level. Crop Science, v.45, p.1958-1864, 2005.

FLORES, P.; BOTELlA, M.A.; MARTÍNEZ, V.; CERDÁ, A. Response to salinity of tomato seedlings with a split-root system: nitrate uptake and reduction. Journal of Plant Nutrition, v.25, p.177-187, 2002.

GULZAR, S.; KHAN, M.A.; UNGAR, I.A. Salt tolerance of a coastal salt marsh grass. Communications in Soil Science and Plant Analysis, v.34, p.2595-2605, 2003.

JELLUM, M.D.; BOSWELL, F.C.; YOUNG, C.T. Nitrogen and boron effects on protein and oil of corn grain. Agronomy Journal, v.65, p.330-331, 1973.

LIMA, G.S. de; SOARES, L.A. dos A.; NOBRE, R.G.; GHEYI, H.R.; SILVA, A.O. da. Crescimento inicial da mamoneira sob 
diferentes salinidades da água de irrigação e doses de nitrogênio. Revista Verde de Agroecologia e Desenvolvimento Sustentável, v.6, p.201-209, 2011.

MARINHO, A.B.; MOREIRA, L.G.; VIANA, T.V. de A.; ALBUQUERQUE, A.H.P.; OLIVEIRA, C.W.; AZEVEDO, B.M. de. Influência da fertirrigação da nitrogenada na produtividade da cultura da mamoeira. Revista Brasileira de Agricultura Irrigada, v.4, p.31-42, 2010.

MEDEIROS, J.F.; LISBOA, R.A.; OLIVEIRA, M. de; SILVA JÚNIOR, M.J. da; ALVES, L.P. Caracterização das águas usadas para irrigação na área produtora de melão da Chapada do Apodi. Revista Brasileira de Engenharia Agrícola e Ambiental, v.7, p.469-472, 2003.

MELHORANÇA, A.L.; STAUT, L.A. Indicações técnicas para a cultura da mamona no Mato Grosso do Sul. Dourados: Embrapa Agropecuária Oeste, 2005. 65p.

MILLER, A.J.; CRAMER, M.D. Root nitrogen acquisition and assimilation. Plant and Soil, v.274, p.1-36, 2005.

MUNNS, R.; JAMES, R.A.; LÄUCHLI, A. Approaches to increasing the salt tolerance of wheat and other cereals. Journal of Experimental Botany, v.57, p.1025-1043, 2006.

NÓBREGA, M.B. de M.; ANDRADE, F.P.; SANTOS, J.W.; LEITE, E.J. Germoplasma. In: AZEVEDO, D.M.P. de; LIMA, E.F. (Ed.). O agronegócio da mamona no Brasil. Brasília: Embrapa Informação Tecnológica, 2001. p.257-280.

NOVAIS, R.F.; NEVES, J.C.L.; BARROS, N.F. Ensaio em ambiente controlado. In: OLIVEIRA, A.J.; GARRIDO, W.E.; ARAUJO, J.D. de; LOURENÇO, S. (Coord.). Métodos de pesquisa em fertilidade do solo. Brasília: Embrapa-SEA, 1991. p.189-253.

RHOADES, J.D.; KANDIAH, A.; MASHALI, A.M. Uso de águas salinas para produção agrícola. Campina Grande: UFPB, 2000. 117p. (Estudos FAO. Irrigação e drenagem, 48).

RODRIGUES, L.N.; NERY, A.R.; FERNANDES, P.D.; BELTRÃO, N.E. de M.; GHEYI, H.R. Crescimento e produção de bagas da mamoneira irrigada com água residuária doméstica.
Revista Brasileira de Engenharia Agrícola e Ambiental, v.13, p.825-835, 2009.

SANTOS, J.F. dos; GRANGEIRO, J.I.T.; OLIVEIRA, M.E.C. de O. Produção da cultura da mamoneira em função da fertilização com cama de galinha. Engenharia Ambiental, v.7, p.169-180, 2010.

SEVERINO, L.S.; FERREIRA, G.B.; MORAES, C.R. de A.; GONDIM, T.M. de S.; CARDOSO, G.D.; VIRIATO, J.R.; BELTRÃO, N.E. de M. Produtividade e crescimento da mamoneira em resposta à adubação orgânica e mineral. Pesquisa Agropecuária Brasileira, v.41, p.879-882, 2006.

SILVA, J.V.; LACERDA, C.F. de; COSTA, P.H.A. da; ENÉAS FILHO, J.; GOMES FILHO, E.; PRISCO, J.T. Physiological responses of $\mathrm{NaCl}$ stressed cowpea plants grown in nutrient solution supplemented with $\mathrm{CaCl}_{2}$. Brazilian Journal of Plant Physiology, v.15, p.99-105, 2003.

SILVA, S.M.S.; ALVES, A.N.; GHEYI, H.R.; BELTRÃO, N.E. de M.; SEVERINO, L.S.; SOARES, F.A.L. Desenvolvimento e produção de duas cultivares de mamoneira sob estresse salino. Revista Brasileira de Engenharia Agrícola e Ambiental, v.12, p.335-342, 2008.

SILVA, S.M.S.; GHEYI, H.R.; BELTRÃO, N.E. de M.; SANTOS, J.W. dos; SOARES, F.A.L. Dotações hídricas em densidades de plantas na cultura da mamoneira cv. BRS Energia. Revista Brasileira de Ciências Agrárias, v.4, p.338-348, 2009.

SILVA, T.R.B. da; LEITE, V.E.; SILVA, A.R.B. da; VIANA, L.H. Adubação nitrogenada em cobertura na cultura da mamona em plantio direto. Pesquisa Agropecuária Brasileira, v.42, p.1357-1359, 2007.

SOUSA, A.E.C.; GHEYI, H.R.; SOARES, F.A.L.; MEDEIROS, E.P. de; NASCIMENTO, E.C.S. Teor de óleo no pinhão manso em função de lâminas de água residuária. Pesquisa Agropecuária Brasileira, v.46, p.108-111, 2011.

TESTER, M.; DAVENPORT, R. Na ${ }^{+}$tolerance and $\mathrm{Na}^{+}$transport in higher plants. Annals of Botany, v.91, p.503-527, 2003.

Recebido em 4 de janeiro de 2012 e aprovado em 2 de maio de 2012 